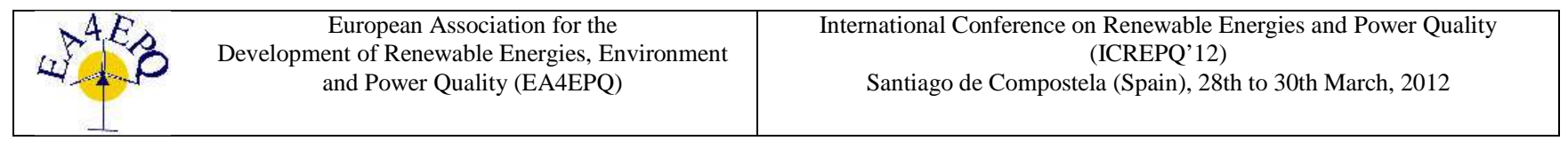

\title{
Air flow prediction and evaluation of ventilation effectiveness with different zonal configurations
}

\author{
N. Guerfala ${ }^{1}$, H. Fellouah ${ }^{1}$, A.Daoud ${ }^{2}$ and N. Galanis ${ }^{1}$ \\ ${ }^{1}$ Department of Mechanical Engineering \\ Université de Sherbrooke \\ Sherbrooke, Québec, J1K 2R1 (Canada) \\ Phone:+1 $8198218000 \# 65641$, \\ e-mails: nasreddine.guerfala@usherbrooke.ca, nicolas.galanis@ usherbrooke.ca, hachimi.fellouah@usherbrooke.ca \\ ${ }^{2}$ Institut de Recherche d'Hydro-Québec \\ Laboratoire des Technologies de l'Énergie (LTE) \\ Shawinigan, Québec, G9N 7N5 (Canada) \\ Phone : +1 819-539-140\#1403 \\ Email : daoud.ahmed@1te.ireq.ca
}

\begin{abstract}
.
This paper proposes a numerical method for the study of ventilation efficiency in buildings. The developed model is validated with the experimental results of Nielsen [5] who tested the isothermal flow in a scaled model of a ventilated room. A zonal method is used to predict airflow patterns in the same ventilated room. The different equations governing the flow in the room were coded in Matlab for different operating conditions, different zonal configurations of the room and different number of cells (control volumes). The efficiency of the ventilation was determined by calculating the number of air changes per hour $(\mathrm{ACH})$ for each cell. The present results show the importance of the inlet air flow rate, the space resolution and the jet inlet dimensions on the determination of air quality.
\end{abstract}

\section{Key words}

Air flow, zonal method, numerical simulation, ventilated room, ventilation efficiency.

\section{Introduction}

The prediction of airflow in enclosed spaces is essential for the design of efficient heating, ventilation and air conditioning (HAVC) systems. Modeling and calculation are used for this purpose to save time and money by avoiding experimentation which is complicated and expensive, particularly in the case of large buildings. The main such methods are the nodal method, CFD (Computational fluid dynamic) and the zonal method.

The nodal, or multizone, method [1] considers each room or floor in a building as a fully-mixed zone by assuming uniform pressure, temperature and chemical concentration within each zone. The model includes control volume expressions of the mass, energy and species conservation equations and is easily solved. Its precision is limited since it relies on empirical correlations for heat and mass transfer. Furthermore, the fully-mixed assumption is not valid for large enclosed spaces (auditoriums, supermarkets, etc) or spaces with displacement ventilation.

CFD models are based on the partial differential equations of fluid mechanics and heat-mass transfer. They simulate the airflow with high resolution by discretizing each part of the building with several hundred grid points. According to Qingyan Chen [2], who presented an overview of methods used to predict ventilation performance in buildings, CFD contributed $70 \%$ of the recent literature on this subject; he noted that "researchers continue to seek more reliable, more accurate, and faster CFD models. However, the effort has yet to produce fruitful results". Thus, for example, the CFD determination of the two-dimensional temperature and velocity fields in an indoor skating rink for a 24-hour period required 24 hours of calculations on a modern desktop computer [3].

An intermediate approach is the zonal method [4] in which the enclosed space is subdivided in a few dozen cells. In each cell, the temperature, air density and species concentration are considered homogenous whereas the pressure varies hydrostatically. The conservation equations for mass and energy are applied to each cell. This approach guarantees more detailed information than the nodal model and requires less time and computer capacity than the CFD approach.

The purpose of the present study is to demonstrate the application of the zonal method for the calculation of ventilation effectiveness in an enclosure with a very high number of air changes per hour $(\mathrm{ACH})$. The enclosure tested by Nielsen et al [5] is used for this purpose. 


\section{Literature review}

The early development of the zonal method has been reviewed by Mergi \& Haghighat [4] and by Daoud \& Galanis [6]. Qingyan Chen [2] indicates that before 2009 most applications of the zonal method were for flows with weak momentum forces and stated that if they were strong, as in a jet or thermal plume regions, "the accuracy of the zonal model simulations would suffer considerably". This limitation had already been noted in the works of Wurtz et al [7] and Musy et al [8]. As a result, specific models have been developed based on the work of Allard et al [9] for boundary layer models, Rajaratnam [10] for jets and Inard [11] for plumes. A complete review of models for specific flows has been presented by Teshome \& Haghighat [12].

The problem under consideration here is the isothermal flow in the ventilated enclosure tested by Nielsen et al [5] illustrated in Figure 1. These experiments were carried out with an inlet air velocity of $15.02 \mathrm{~m} / \mathrm{s}$ which leads to an extremely high number of $\mathrm{ACH}$ (approximately equal to 58.5, see equation 6 for ACH relation). Mora et al [13] considered that this flow field is two-dimensional even though the experimental results by Nielsen clearly show that the flow field is three-dimensional. Their numerical results were in fairly good agreement with measurements of the jet velocity profile in the $\mathrm{z}=0$ plane but did not give good agreement in the recirculation region (lower part of the enclosure). Daoud \& Galanis [6] proposed a new 3D model for the air velocity in the wall jet and obtained better agreement than Mora et al [13] between the calculated and measured velocity profiles at all the positions for which measurements are available. As a result of sensitivity tests they recommend that the shear stress approximation should be privileged over the conventional method and the pressure outlet condition should be used when there is more than one outlet.

Recently, Abadie et al [14] presented a detailed comparison of experimental results with predictions by CFD, Coarse-Grid CFD, FFD (Fast Fluid Dynamics) and the zonal method for isothermal 2D flow of air in a large (9 $\mathrm{m}$ long, $3 \mathrm{~m}$ wide, $3 \mathrm{~m}$ high) room. For the zonal method they used a modified 2D jet model which takes into account the increase of the jet mass flow rate due to entrainment and recirculation as well as different diffusion coefficients for different cell interfaces. These comparisons show that the proposed zonal model returns better results than the Coarse-Grid CFD and FFD methods; furthermore, the calculations with the zonal method are faster. However, as the authors of this study point out, 2D air jet models are inadequate for many practical cases.

In view of these remarks, the present study uses the 3D wall jet model proposed by Daoud \& Galanis [6] to predict the velocity profiles, mass flow rates and number of $\mathrm{ACH}$ for selected zones in the enclosure studied by Nielsen et al [5]. The effect of the number of zones, size of the air inlet and inlet velocity of the jet on these results is presented and analyzed.

\section{Problem Modelling}

Figure 1 shows the dimensions of the cavity tested by Nielsen et al [5], the coordinate system as well as the positions and dimensions of the air inlet and outlet. The experiments were carried out by Nielsen et al with an inlet air velocity of $15.02 \mathrm{~m} / \mathrm{s}$ which corresponds to a mass flow rate of $14.7 \mathrm{~kg} / \mathrm{h}$ and a Reynolds number $\mathrm{Re}=5000$ based on the inlet slot height $(\mathrm{h}=5.008 \mathrm{~mm})$ [5].

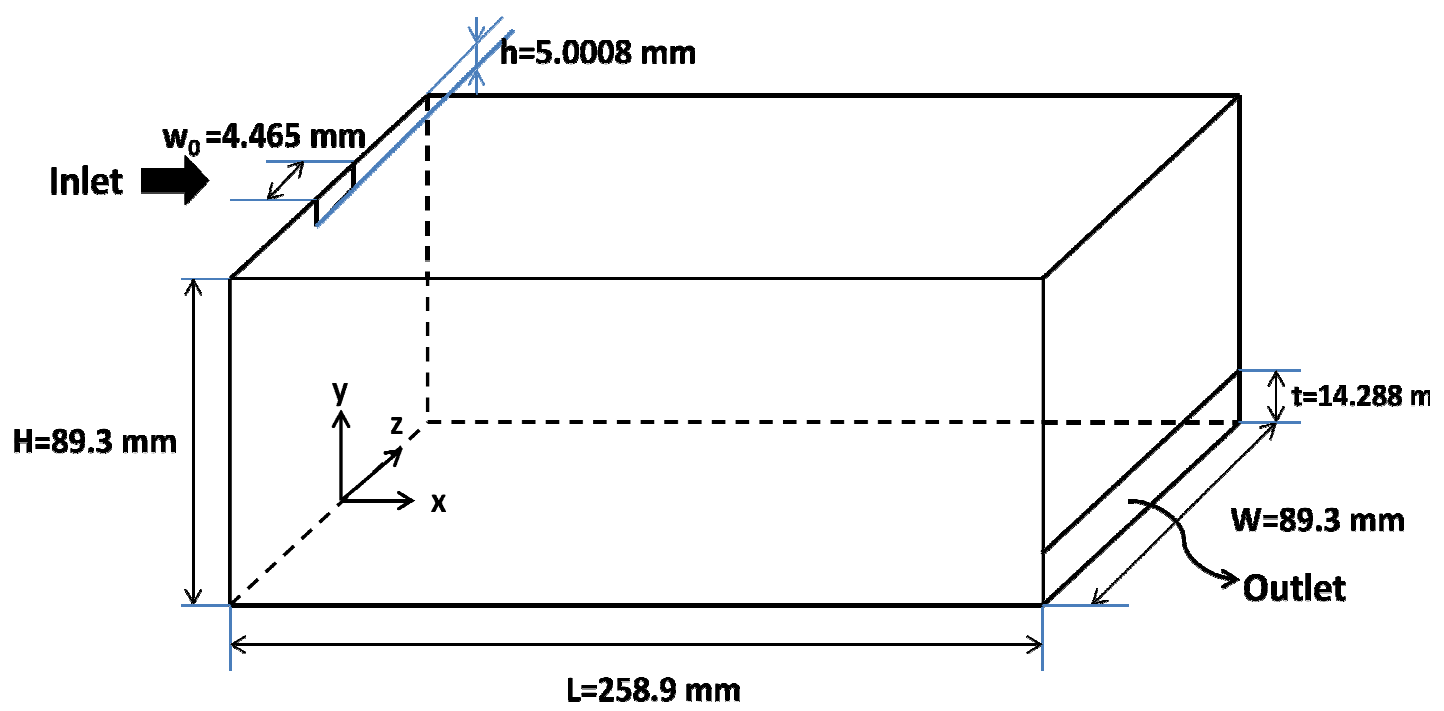

Fig. 1. Schematic representation of the tested enclosure. 
The following expressions for the air velocity within a three-dimensional wall jet were proposed by Daoud \& Galanis [6] and are used in the present study to represent the 3D flow field:

$$
\begin{array}{r}
v\left(x^{\prime}, y^{\prime}, z^{\prime}\right)=v_{0} K d \exp \left(-a\left(\frac{z^{\prime}}{b \cdot\left(z^{\prime}+c w_{0}\right)}\right)^{2}\right) \sqrt{\frac{b_{0}}{x^{\prime}+c b_{0}}} \\
\left(\frac{y}{b\left(x+c b_{0}\right)}\right)^{\frac{1}{7}}\left[1-\operatorname{erf}\left(\frac{e y}{b\left(x+c b_{0}\right.}\right)\right]
\end{array}
$$

$h(x)=0.16\left(x+10 b_{0}\right)$

$w(x)=0.251\left(x+10 w_{0}\right)$

Where $h$ is the height of the jet (m), $w$ is the width of the jet $(\mathrm{m})$ and $(x, y, z)$ are the Cartesian coordinates. The subscript 0 in the equations corresponds to the initial conditions.

This formulation (Eqs. 1 to 3 ) is based on the suggestions of Rajaratnam [10] who postulated that the 3D wall jet is a combination of the 2D wall jet in the XY plane and a free plane jet in the XZ plane. As a consequence, values of the constants in Eqs. (1)-(3) are equal to the corresponding ones for these two simpler jets:

$a=0.693 ; b=0.097 ; c=10 ; d=1.48 ; e=0.68 ; K=4.6$.

In order to calculate the velocities, two different zonal configurations were used in the present study. The first one was obtained by dividing the test cavity into 36 cells ( 4 in the y direction and 3 in each of the other two directions) as described in the study of Daoud \& Galanis [6]. The second configuration used 48 cells ( 3 in the $z$ direction and 4 in each of the two other directions) which corresponds to the present study. Figure 2 presents the 48 cells zonal configuration and illustrates the dimensions used for the subdivision of the enclosure and the numbering of the cells. In the $\mathrm{z}$ direction, the two zonal configurations (36 and 48 cells) contain a central zone $(|z| \leq 26.2 \mathrm{~mm})$ and two symmetrical side zones $(26.2 \mathrm{~mm} \leq|\mathrm{z}| \leq 44.65 \mathrm{~mm})$.

The mass flow rate $m_{i, j}$ crossing a vertical interface common to the cell $\mathrm{i}$ and $\mathrm{j}$ depends on the difference between the corresponding average pressures. The conservation equations of mass are applied to each cell and the mass flow rates are given by Eqs. (4) and (5) with the discharge coefficient $\mathrm{C}_{\mathrm{d}}=15$.

$\dot{m}_{i, j}=\varepsilon_{i, j} \cdot \sqrt{2 \rho_{i}} \cdot C_{d} \cdot A_{i} \cdot\left|P_{i}-P_{j}\right|^{n}$

And in case of horizontal interface:

$\dot{m}_{i, j}=\varepsilon_{i, j} \cdot \sqrt{2 \rho_{i}} \cdot C_{d} \cdot A_{i} \cdot\left|P_{i}-P_{j}-\frac{1}{2}\left(\rho_{i} g h_{i}+\rho_{j} g h_{j}\right)\right|^{n}(5)$

Where $\mathrm{n}$ is an exponent depending of the flow regime; 0.5 for turbulent flow and 1 for laminar flow.

$\varepsilon_{\mathrm{ij}}$ is a constant depending on flow direction $( \pm 1)$
Calculated velocities were obtained by coupling the 3D wall jet model with the conventional zonal model (see reference [6] for more details).

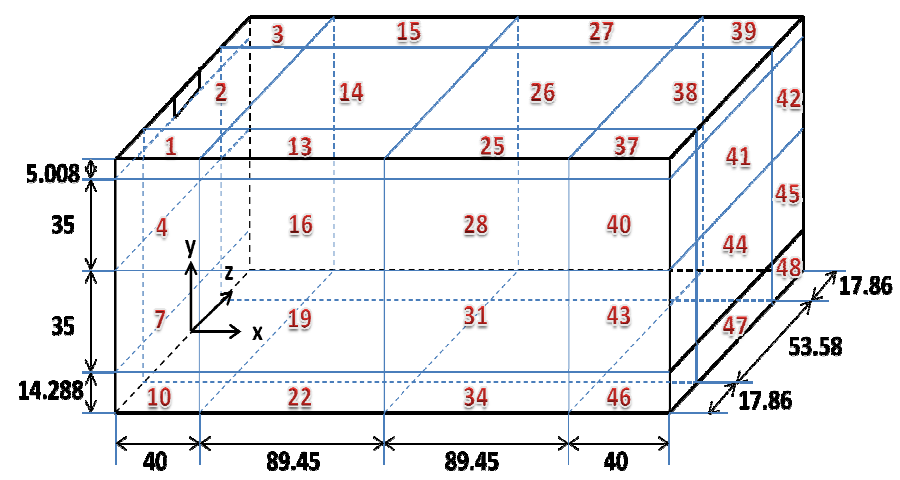

Fig. 2. 48 cells zonal configuration. All dimensions are in $\mathrm{mm}$.

\section{Results}

To obtain the axial evolution of the volumetric flow rate in the room, Eq. (1) is integrated numerically through the local jet section $h(x)$ by $w(x)$ (Eqs. 2-3). The corresponding normalized result, shown in Fig. 3, is represented accurately by the following Boltzmann function:

$\frac{Q\left(x^{\prime}\right)}{Q_{0}}=A_{2}+\frac{A_{1}-A_{2}}{1+e^{\left(\frac{x-A_{0} x_{0}}{A_{0} d x}\right)}}$

With:

$A_{1}=1.43199, A_{2}=2.15091, x_{0}=175.6188$, $d x=196.11077$

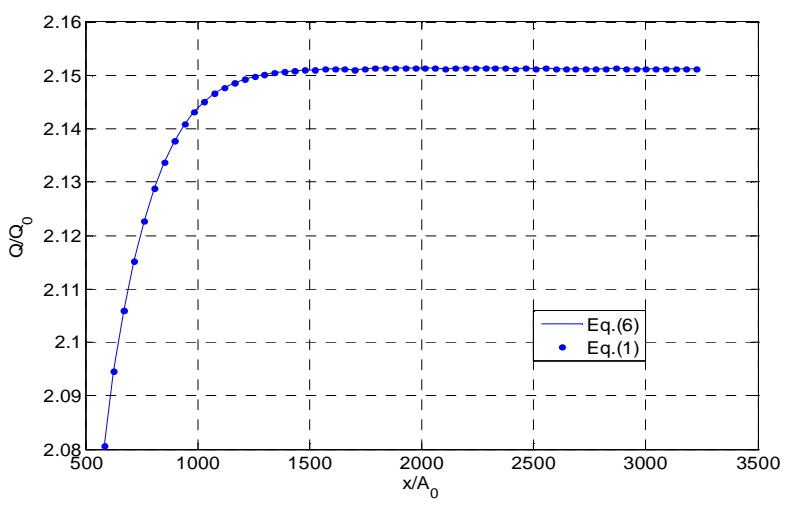

Fig. 3. Boltzmann fit of $\mathrm{Q} / \mathrm{Q}_{0}=\mathrm{f}\left(\mathrm{x} / \mathrm{A}_{0}\right)$

Figures 4 and 5 show the axial mean velocity profile, normalized by the inlet mean velocity, in the symmetry plane $(\mathrm{z}=0)$ for two different axial positions in the cavity. The present result (48 cells) is compared to the zonal configuration scenario (36 cells) of Daoud and Galanis [6] and to the experimental results of Nielsen et al [5]. 


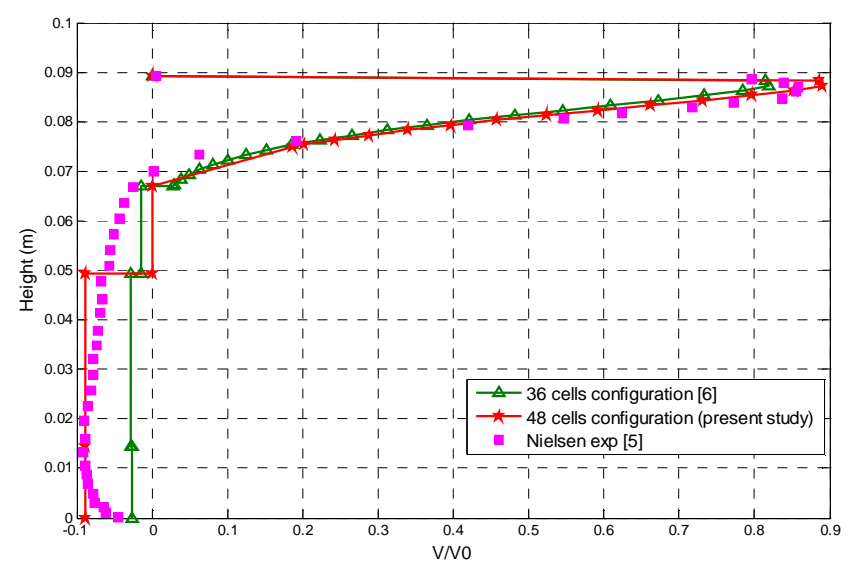

Fig. 4. Velocity profiles at $\mathrm{x} / \mathrm{H}=1$ and $\mathrm{z} / \mathrm{W}=0\left(\mathrm{P}_{\mathrm{out}}=\mathrm{P}_{\mathrm{atm}}\right)$

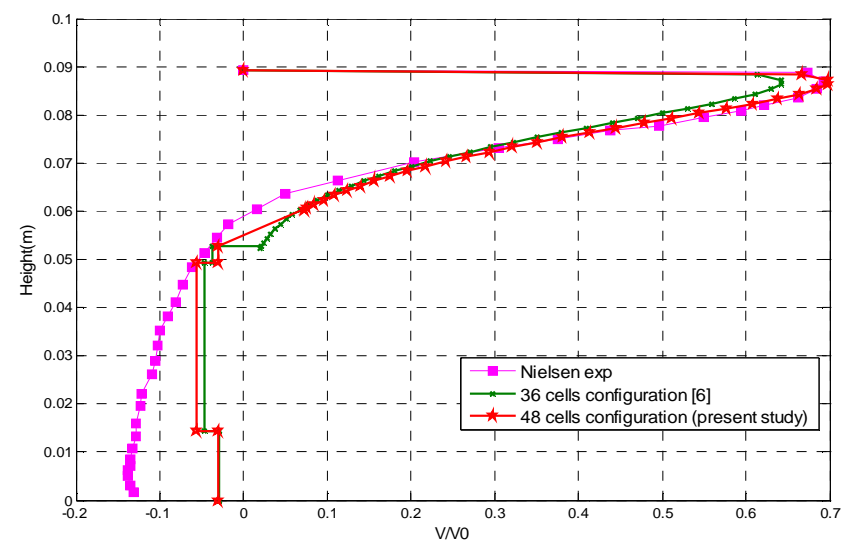

Fig. 5. Velocity profiles at $\mathrm{x} / \mathrm{H}=2$ and $\mathrm{z} / \mathrm{W}=0\left(\mathrm{P}_{\text {out }}=\mathrm{P}_{\mathrm{atm}}\right)$

The comparison between the two scenarios demonstrate that improved correlation with experimental results was achieved using the new 48 cells zonal configuration. It is evident that the results obtained here with the 48 cells configuration are in very good agreement with the experimental results. These results indicate that the increase in the number of cells (space resolution) improves the quality of the airflow predictions in an enclosure contrary to the opinion expressed in previous studies $[6$, 7].

\section{A. Ventilation Effectiveness}

In order to evaluate the ventilation effectiveness in the cavity, the 'number of air changes per hour' (ACH) is calculated in some significant cells. The number of $\mathrm{ACH}$ is a measure of how many times the air within a defined space (normally a room or house) is replaced. It represents the ventilation efficiency in an enclosure. This number is given by equation Eq. 6 .

$$
\mathrm{ACH}=\frac{3600 * Q}{V}
$$

With:

ACH: Number of air chages per hour

Q: Volumtric flow rate of air $\left(\mathrm{m}^{3} / \mathrm{s}\right)$

V: Space volume $\left(\mathrm{m}^{3}\right)$

The cells under consideration are located at the high corners $(1,3,37$ and 39) and in the centre of the enclosure facing the jet (14, 17 and 29). The results are summarised in Table 1 where all the ACH numbers are normalised by the ACH of cell number 2. From this table it is clear that the code gives good results since the air flow rate at each cell is well conserved.

Table 1- Number of ACH for some cells of the enclosure

\begin{tabular}{|c|c|c|c|c|}
\hline $\begin{array}{c}\text { Cell } \\
\#\end{array}$ & $\begin{array}{c}\text { Volume } \\
\left(\mathbf{c m}^{\mathbf{3}}\right)\end{array}$ & $\begin{array}{c}\text { Inlet Air } \\
\text { flow rate } \\
\mathbf{Q}_{\text {in }} \\
\left(\mathbf{m}^{\mathbf{3}} / \mathbf{s}\right)\end{array}$ & $\begin{array}{c}\text { Outlet } \\
\text { Air flow } \\
\mathbf{Q}_{\text {out }} \\
\left(\mathbf{m}^{\mathbf{3}} / \mathbf{s}\right)\end{array}$ & $\begin{array}{c}\text { Normalised } \\
\text { number of } \\
\text { changes } \\
\text { per hour }\end{array}$ \\
\hline $\mathbf{1}$ & 3.57 & 0.023 & 0.023 & 1.155 \\
\hline $\mathbf{2}$ & 10.70 & 0.060 & 0.060 & 1 \\
\hline $\mathbf{3}$ & 3.57 & 0.023 & 0.023 & 1.155 \\
\hline $\mathbf{1 4}$ & 24.00 & 11.340 & 11.340 & 83.191 \\
\hline $\mathbf{1 7}$ & 168.00 & 11.320 & 11.320 & 11.863 \\
\hline $\mathbf{2 9}$ & 168.00 & 20.991 & 20.991 & 21.999 \\
\hline $\mathbf{3 7}$ & 3.57 & 0.015 & 0.015 & 0.750 \\
\hline $\mathbf{3 9}$ & 3.57 & 0.015 & 0.015 & 0.750 \\
\hline $\mathbf{4 7}$ & 30.60 & 0.083 & 0.083 & 0.476 \\
\hline
\end{tabular}

\section{B. Parametric study}

In this section, the effects of the jet inlet velocity and the jet inlet dimensions on the ventilation efficiency are presented and analyzed. The results are given only for the previously selected cells. Recall the ventilation efficiency is evaluated here by the normalized $\mathrm{ACH}$.

First, three inlet velocities of the jet were tested: $\mathrm{v}_{0}=15.02 \mathrm{~m} / \mathrm{s}, \mathrm{v}_{0}=7.5 \mathrm{~m} / \mathrm{s}$ and $\mathrm{v}_{0}=30 \mathrm{~m} / \mathrm{s}$. Then, the number of $\mathrm{ACH}$ was evaluated for each cell. The computed results were unchanged for cells 1, 3, 37 and 39. The variation of the ACH is reported in Fig. 6 for the cells 14,17 and 29 where the variation pronounced.

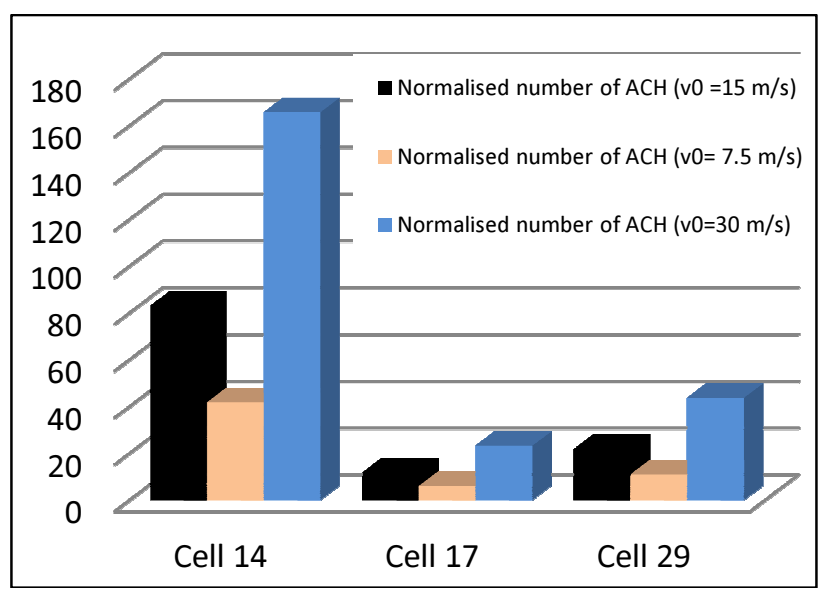

Fig. 6. Effect of the jet inlet velocity on the ventilation efficiency ACH

It is clear from Fig. 6 that the number of ACH increases when the inlet velocity increases and declines when the inlet velocity decreases. These results in fact indicate that the number of $\mathrm{ACH}$ for the cells across the jet $(14,17$ and 29) is proportionally related to the jet inlet velocity 
$\mathrm{v}_{0}$. Nevertheless, this effect is only local since the number of $\mathrm{ACH}$ remains the same (unchanged) for the other tested cells $(1,3,37$ and 39).

Second, the height of the air jet inlet was varied from $\mathrm{h}=$ $5.0008 \mathrm{~mm}$ to $\mathrm{h}=10 \mathrm{~mm}$ and $\mathrm{h}=30 \mathrm{~mm}$ to evaluate its effect on the ventilation effectiveness in different cells of the cavity. The corresponding results show that the numbers of $\mathrm{ACH}$ for the four upper corner cells (1, 3, 37 and 39) were unchanged compared to those presented previously in Table I.

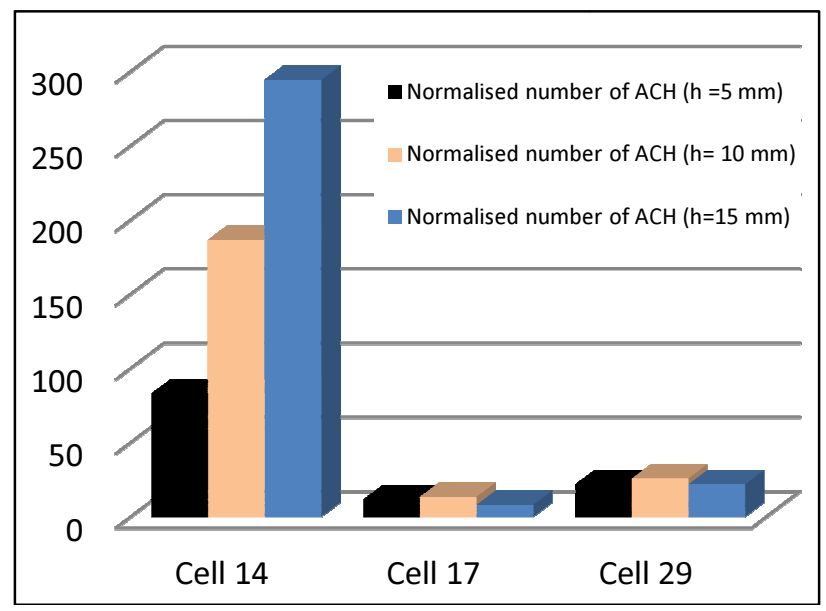

Fig. 7. Effect of the jet inlet height on the ventilation efficiency $\mathrm{ACH}$

Figure 7 illustrates the effect of the variation of the inlet height on the number of changes per hours $(\mathrm{ACH})$ for the cells across the jet $(14,17$ and 29). It can be noted that changing this parameter has a low impact on the $\mathrm{ACH}$ of cells 17 and 29 but strongly affects the ACH of cell 14 .

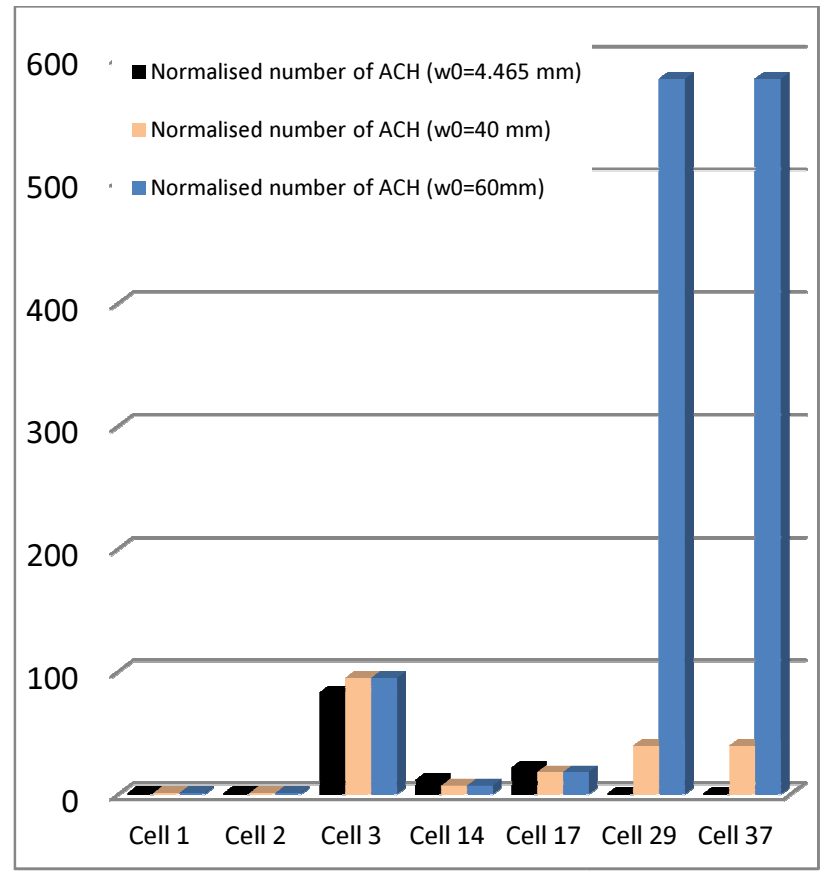

Fig. 8. Effect of the jet inlet width on the ventilation efficiency $\mathrm{ACH}$
Finally, the width of the air inlet (originally $\mathrm{w}_{0}=4.465$ $\mathrm{mm}$ ) was increased to $\mathrm{w}_{0}=40 \mathrm{~mm}$ and $\mathrm{w}_{0}=60 \mathrm{~mm}$. As we can see from Fig. 8, the change of the inlet width affects the ACH number of all the selected cells. While the number of air changes has not varied much for cells 1,3 and 17 it has dramatically increased for cells 37 and 39. Thus this indicates that the augmentation of the inlet width ameliorates the ventilation effectiveness.

\section{Conclusion}

In order to evaluate the quality or effectiveness of the ventilation, the normalized $\mathrm{ACH}$ indicator was used in this study for different cells in the cavity tested by Nielsen et al [5].

Contrarily to what is claimed by Daoud and Galanis [6] and Wurtz et al [7] whose work showed that the increase in the number of cells (space resolution in the zonal model) does not improve the quality of the airflow field in an enclosure, the present work demonstrated the importance of the number of zones on the ventilation efficiency.

It has been proved in this paper that the inlet jet velocity and the inlet dimensions influence the ventilation effectiveness of the enclosure.

\section{Acknowledgement}

This study is financed by the Natural Sciences and Engineering Research Council (NSERC) of Canada.

\section{References}

[1] J. Axley, "Multizone airflow in buildings: history and theory”, HVAC\&R Research 2007, Vol. 13 no. 6, pp. 907-928.

[2] Qingyan Chen, "Ventilation performance prediction for buildings: A method overview and recent applications", Building and Environment 2009, Vol. 44, pp. 848-858.

[3] L. Seghouani, A. Daoud and N. Galanis, "Prediction of yearly energy requirements of indoor ice rinks", Energy and Buildings 2009, Vol. 41, pp. 500-511.

[4] A.C. Megri and F. Haghighat, "Zonal modeling for simulating indoor environment of buildings: review, recent developments and applications", Int. J. of Ventilation 2007 , Vol. 6 no. 2, pp. 887-905.

[5] P.V. Nielsen, A. Restivo and J.H. Whitelaw, "Buoyancyaffected flows in ventilated rooms", Numerical Heat transfer 1979, Vol. 2, pp. 115-127.

[6] A. Daoud and N. Galanis, "Prediction of airflow patterns in a ventilated enclosure with zonal methods", Applied Energy 2008, Vol. 85, pp. 439-448.

[7] E. Wurtz, J.M. Nataf and W. Winkelmann, "Two- and threedimensional natural and mixed convection simulation using modular zonal models in buildings", Int $\mathbf{J}$ of Heat and Mass Transfer 1999, Vol. 42 no. 5, pp. 923-940.

[8] M. Musy, E. Wurtz, W. Winkelmann and F. Allard, "Generation of a zonal model to simulate natural convection in a room with a radiative/convective heater", Building and Environment 2001, Vol. 36 no. 5, pp. 589-596.

[9] F. Allard, C. Inard and J. Simoneau, "Phénomènes convectifs intérieurs dans les cellules d'habitation. Approches expérimentales et numériques, Revue Générale de Thermique 1990, Vol. 29, pp. 216-225. 
[10] N. Rajaratnam, "Turbulent jets", Elsevier Scientific Publishing Co, Netherlands (1976).

[11] C. Inard, "Contribution à l'étude du couplage thermique entre une source de chaleur et un local", INSA de Lyon, France (1988).

[12] E.J. Teshome and F. Haghighat, "Zonal models for indoor air flow - a critical review", Int. J. of Ventilation 2004, Vol. 3 no. 2, pp. 119-129.
[13] L. Mora, A.J. Gadgil and E. Wurtz, "Comparing zonal and CFD model predictions of isothermal indoor airflows to experimental data”, Indoor Air 2003, Vol. 13, pp. 77-85.

[14] M.O. Abadie, M.M. de Camargo, K.C. Mendonça and P. Blondeau, "Improving the prediction of zonal modeling for forced convection airflows in rooms", Building and Environment 2012, Vol. 48, pp. 173-182. 